\title{
Perceived Stress, Anxiety and Insomnia among Nursing Staff in Saudi Arabia during the 2019 Novel Coronavirus Disease Pandemic
}

\author{
Magda M. Agameel1,2*, Sahar A. Abd-El Mohsen1,3, Nagda A. Dyab4,5, Amal Yousef Abdelwahed ${ }^{6,7^{*}}$, \\ Razan Adel Fakieh ${ }^{6}$ \\ ${ }^{1}$ Department of Nursing, College of Applied Medical Sciences, Prince Sattam Bin Abdulaziz University, Wadi Eldawaser, Saudi Arabia \\ ${ }^{2}$ Department of Gerontolgical Nursing, Faculty of Nursing, Damanhour University, Damanhour, Egypt \\ ${ }^{3}$ Department of Medical Surgical Nursing, Faculty of Nursing, Asyut University, Asyut, Egypt \\ ${ }^{4}$ Department of Nursing, Alghad International College for Applied Medical Science, Abha, Saudi Arabia \\ ${ }^{5}$ Department of Community Health Nursing, Faculty of Nursing, South Valley University, Qena, Egypt \\ ${ }^{6}$ Department of Public Health, College of Health Sciences, Saudi Electronic University, Dammam, Saudi Arabia \\ ${ }^{7}$ Department of Community Health Nursing, Faculty of Nursing, Damanhour University, Damanhour, Egypt \\ Email: *Magdaalgameel@yahoo.com, *a.elnabasy@seu.edu.sa
}

How to cite this paper: Agameel, M.M. Mohsen, S.A.A.-E., Dyab, N.A., Abdelwahed, A.Y. and Fakieh, R.A. (2022) Perceived Stress, Anxiety and Insomnia among Nursing Staff in Saudi Arabia during the 2019 Novel Coronavirus Disease Pandemic. Open Journal of Nursing, 12, 1-11.

https://doi.org/10.4236/ojn.2022.121001

Received: November 1, 2021

Accepted: January 23, 2022

Published: January 26, 2022

Copyright $\odot 2022$ by author(s) and Scientific Research Publishing Inc. This work is licensed under the Creative Commons Attribution International License (CC BY 4.0).

http://creativecommons.org/licenses/by/4.0/ (c) (i) Open Access

\begin{abstract}
Background: Nursing staff exposed to 2019 novel coronavirus disease which might be at the increased risk of development mental health problems such as stress, anxiety and insomnia. Objectives: To estimate the spread of stress, anxiety and insomnia among the nursing staff who are working at Asir central hospital, Kingdom of Saudi Arabia. Methods: This study was a descriptive cross-sectional study, that involved with a 53 (44 Female and 9 Male) nurses who are working at Asir central hospital, Kingdom of Saudi Arabia. A convenient sampling technique was used to select the participants during the period from October to the mid of November 2020. A structured closed-ended questionnaire was used related with three standard tools (The Perceived Stress Scale, Generalized Anxiety Disorder and the Insomnia severity index). Results: The results revealed that $90.6 \%$ of participants had moderate stress and $7.5 \%$ showed low stress. Regarding anxiety, $37 \%$ of nurses had mild anxiety, $28.3 \%$ and $34 \%$ had moderate and severe anxiety, respectively. Moreover, subthreshold insomnia was observed in $60.4 \%$ and clinical insomnia in $15 \%$ of study candidates. Additionally, a statistically significant association was found between levels of stress, anxiety and insomnia and the age of the studied nurses $(P=0.00)$. Conclusion: The results of this study showed that the spread of stress, anxiety and insomnia, was higher than some studies which have been reported in the previous researches. Significant difference was observed between mental distress and age of nurses, while there was no significant dif-
\end{abstract}


ference between the studied mental health problems and gender.

\section{Keywords}

Anxiety, COVID-19, Nursing Staff, Insomnia, Stress

\section{Introduction}

The 2019 Coronavirus Disease (COVID-19), is a severe acute respiratory syndrome caused by severe acute respiratory syndrome coronavirus (SARS-CoV-2). A novel coronavirus outbreak of pneumonia was found in December 2019 [1]. However, the number of people suffering from the Coronavirus disease (COVID19) has increased globally; the World Health Organization (WHO) announced it to be pandemic [2].

It is transmitted primarily through respiratory droplets and direct or indirect contact. Droplet transmission occurs when a person is existing on distance of one meter of someone who has symptoms such as coughing or sneezing. Indirect contact with surfaces in the immediate environment or with objects which are used by an infected person as stethoscope, can also transmit the virus. Airborne transmission can occur in specific circumstances and procedures or support treatments that generate aerosols as endotracheal intubation and bronchoscopy [3] [4].

It has been reported that mental health has been adversely affected by workplace stress among health care professionals (HCPs) who are caring for patients with COVID-19 [5]. They are highly vulnerable to experiencing physical exhaustion, sleep problems [6], Stress and or fear of being infected and transmitting the virus among their relatives [7]. Mental health assessment, support, and treatment, deemed important elements of the response to COVID-19 outbreak [8]. Health care workers (HCWs) who worked during the COVID-19 outbreak were more likely to have poor sleep quality compared to other occupational groups [9].

According to multiple researches, for example, a recent study in Poland indicated that COVID-19 infection increases depression, anxiety, and sleep disturbances among healthcare professionals [10]. Similar findings were obtained in one study in Iran [11] and another in China [12], which indicated that nurses suffer from more stress, excessive physical tiredness, anxiety, and insomnia when they are providing care, and resulting in lower patient care quality. Nurses and physicians working in public hospitals in Greece, had sleep problems during the epidemic, according to another study [13], which discovered that nurses face more stress, intense physical tiredness, anxiety, and insomnia while providing treatment, resulting in lower patient quality. Also, COVID-19 exposure had a significant influence on healthcare professionals' trauma, psychological discomfort, and turnover intention, according to a conducted study in Pakistan on the mental health of nurses [14]. Using various scales in the Kingdom of Saudi Arabia, several research [15] [16] [17] [18] have investigated the potential influence 
of COVID 19 in health care workers and the general public. Using the Patient Health Questionnaire (PHQ-9) and the Generalized Anxiety Disorder (GAD-7) questionnaire.

\section{Aim of the Study}

This study aimed to assess the perceived stress, anxiety and insomnia among nursing staff in Kingdom of Saudi Arabia during the 2019 novel coronavirus disease pandemic.

\section{Methods}

\subsection{Study Design and Setting}

This hospital-based descriptive cross-sectional study was conducted in Asir central hospital, Abha, Saudi Arabia. This hospital was established in 1982 with capacity of 574 beds, and since this establishment, it provides a wide range of services through healthcare professionals and trainees from all specialties.

\subsection{Participants}

A convenience sample of all available nursing staff working with COVID 19 positive patients enrolled in this study. The working nursing staff at the hospital (including full-time nurse and part-time nurses) at the time of data collection (from first of October to the mid of November 2020), and have cared about COVID19 positive patients, were invited to participate in the study. A total of 53 nurses agreed to join the study.

\subsection{Data Collection}

Data was collected from participants using a structured, close-ended, self-administered questionnaire. The questionnaire composed of four sections as follows; Section one: Demographic characteristics of the participants: age, sex, marital status, education and occupation. Section two: the Perceived Stress Scale (PSS10); this scale was developed by Levenstein et al. 1993 [19]. The PSS-10 is the most widely used psychological instrument for measuring the perception of stress. It is a measurement of the degree to which situations in one's life are appraised as stress. Section three: Generalized Anxiety Disorder (GAD-7); this scale was developed by Spitzer et al. 2006 [20] GAD-7 is a seven-item instrument that is used to measure or assess the severity of generalized anxiety disorder. Section four: Insomnia severity index; the Insomnia Severity Index includes seven questions developed by Morin 1993 [21].

\subsection{Data Analysis}

The collected data was entered and analyzed using statistical package software (SPSS) version 25. Data was presented using descriptive statistics as frequencies and percentages, Mean $\pm \mathrm{SD}$, correlation analysis was done using (F test). Statistical significance was considered at $\mathrm{P}$-value $<0.05$. 
Regarding the analysis of the used tools; In the Perceived Stress Scale the overall score of 0 to 13 is considered as low stress, from 14 to 26 is moderate stress and from 27 to 40 is severe perceived stress [19]. Additionally, in Generalized Anxiety Disorder (GAD-7) a score less than five on the GAD-7 represents no anxiety, scores of 5, 10 and 15 are taken as the cut-offs for mild, moderate, and severe anxiety, respectively [20]. However, in insomnia severity index the seven answers are added up to get a total score, a total of 0 to 7 represents "no clinically significant insomnia", from 8 to 14 is "Sub threshold insomnia", from 15 to 21 is "Clinical insomnia (moderate severity)", and from 22 to 28 is "Clinical insomnia (severe)" [21].

\subsection{Ethical Considerations}

This study was approved from Al Ghad International Colleges for Applied Medical Sciences. An informed consent was taken from each nurse in the study after explaining the aim and nature of the study, nurses were ensured of their right to withdraw from the study at any time without any rationale.

\section{Results}

1) A total of 53 nurses participated in the study, the majority of them (83.1\%) were females and half of them aged between 30 to 40 years old with the mean age 30.71 ( $\mathrm{SD}=5.01$ ). Regarding marital status; $86.8 \%$ of the sample were married, 7.5\% single and 5.7\% were divorced. Regarding education; $81.1 \%$ were having a bachelor degree of nursing and $18.9 \%$ were having a diploma nursing degree. Regarding nurse's occupational position; $94.3 \%$ were staff nurses and $5.7 \%$ were head nurses as depicted in Table 1.

2) Regarding participant's Insomnia severity index; $60.40 \%$ of the studied nurses showed sub-threshold insomnia, $24.60 \%$ had no clinically significant insomnia while $15 \%$ of them had clinical insomnia (Figure 1). Additionally, regarding participant's generalized anxiety disorder scale; $37.70 \%$ of the studied nurses have a mild anxiety, $34 \%$ have a moderate anxiety and $28.30 \%$ have a severe anxiety (Figure 2), and regarding perceived stress among participants; $90.60 \%$ have moderate perceived stress, $7.50 \%$ have low perceived stress, and $1.90 \%$ have high perceived stress, $90.6 \%$ of them have moderate perceived stress (Figure 3 ).

3) A statistically significant association was found between the participant's age and the insomnia severity index $(\mathrm{p}=0.001)$ generalized anxiety disorder score $(\mathrm{p}=0.001)$ and perceived stress scale $(\mathrm{P}=0.001)$ (Table 2).

4) No association was found between the participant's gender and the insomnia severity index, generalized anxiety disorder score and perceived stress scale.

\section{Discussion}

This is a hospital-based descriptive cross-sectional study in Asir central hospital, Abha, Kingdome Saudi Arabia. The study revealed a considerable level of stress, 
anxiety and clinical insomnia among working nursing staff in the studied hospital.

The COVID-19 pandemic is a worldwide crisis that has produced exceptional changes in our lives. Stress, anxiety, and impaired sleep, are major problems facing health care workers, especially nurses. The nurses play a main role in combating this disease, and improving their mental health, which deemed an essential to control the pandemic [22].

Table 1. Demographic characteristics of survey participants.

\begin{tabular}{|c|c|c|c|}
\hline & Variables & Number & Percent \\
\hline \multicolumn{4}{|c|}{ Age group } \\
\hline & $20-<30$ & 24 & 45.2 \\
\hline & $30-<40$ & 27 & 51.0 \\
\hline & 40 and more & 2 & 3.8 \\
\hline \multicolumn{4}{|c|}{ Sex } \\
\hline & Male & 9 & 16.9 \\
\hline & Female & 44 & 83.1 \\
\hline \multicolumn{4}{|c|}{ Marital status } \\
\hline & Single & 4 & 7.5 \\
\hline & Married & 46 & 86.8 \\
\hline & Divorced & 3 & 5.7 \\
\hline \multicolumn{4}{|c|}{ Education } \\
\hline & Diploma nursing & 10 & 18.9 \\
\hline & Bachelor's degree & 43 & 81.1 \\
\hline \multicolumn{4}{|c|}{ Occupation } \\
\hline & Head nurse & 3 & 5.7 \\
\hline & Staff nurse & 50 & 94.3 \\
\hline \multicolumn{4}{|c|}{ Insomnia severity index } \\
\hline $70.00 \%$ & \multirow{2}{*}{\multicolumn{3}{|c|}{$60.40 \%$}} \\
\hline $60.00 \%$ & & & \\
\hline \multicolumn{4}{|l|}{$50.00 \%$} \\
\hline \multicolumn{4}{|l|}{$40.00 \%$} \\
\hline $30.00 \%$ & \multicolumn{3}{|l|}{$24.60 \%$} \\
\hline $20.00 \%$ & & & $15 \%$ \\
\hline \multicolumn{4}{|l|}{$10.00 \%$} \\
\hline \multicolumn{3}{|l|}{$0.00 \%$} & Clinical insomnia \\
\hline & insomnia & & \\
\hline
\end{tabular}

Figure 1. Participant's distribution by Insomnia severity index. 


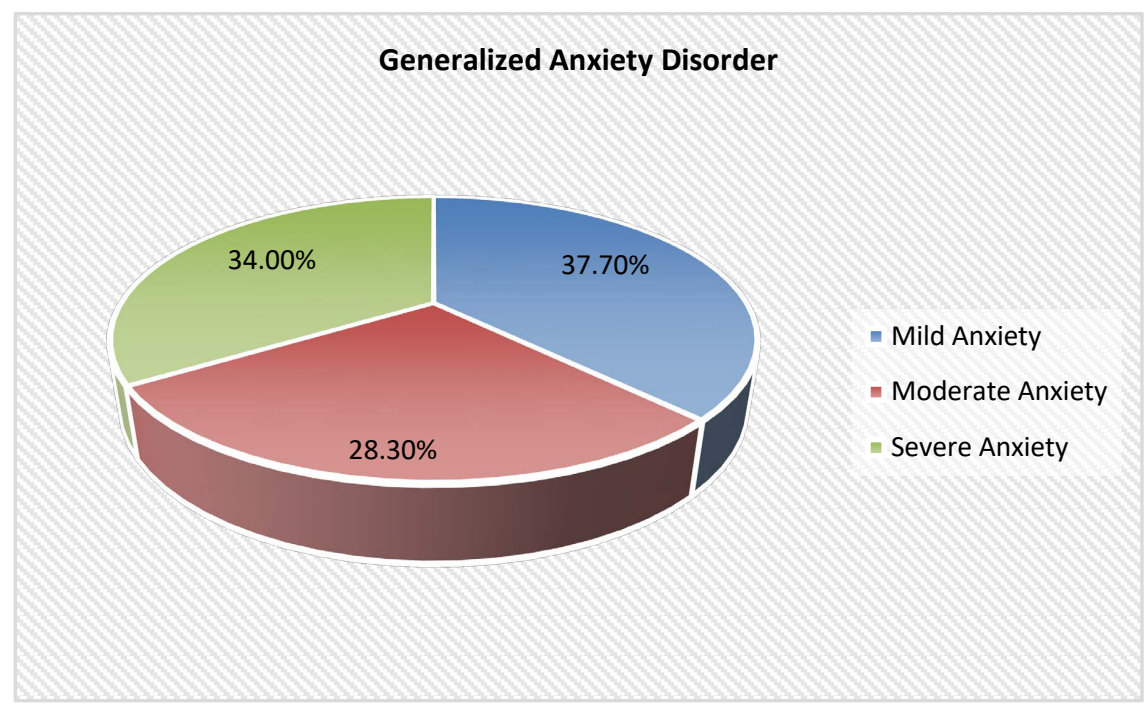

Figure 2. Participant's distribution by generalized anxiety disorder scale.

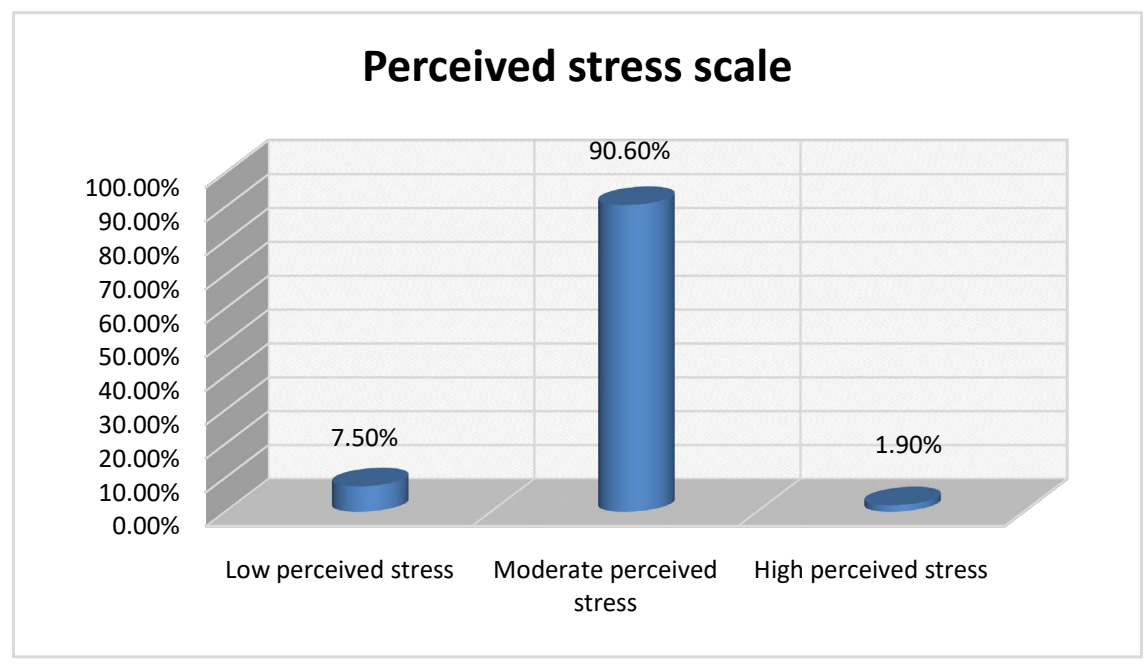

Figure 3. Perceived stress among participants.

Table 2. Relation between mean age and mean insomnia severity index, generalized anxiety disorder score and perceived stress scale in the studied sample.

\begin{tabular}{cccccc}
\hline & & df & Mean Square & F & Sig. \\
\hline $\begin{array}{c}\text { Insomnia Severity } \\
\text { Index }\end{array}$ & Between Groups & 15 & 54.110 & 5.546 & 0.001 \\
& Within Groups & 38 & 9.757 & & \\
\hline $\begin{array}{c}\text { Generalized Anxiety } \\
\text { Disorder }\end{array}$ & Between Groups & 15 & 54.876 & 4.179 & 0.001 \\
& Within Groups & 38 & 13.131 & & \\
\hline \multirow{2}{*}{$\begin{array}{c}\text { Perceived Stress Scale } \\
\text { Between Groups }\end{array}$} & 15 & 36.634 & 3.362 & 0.001 \\
& Within Groups & 38 & 10.897 & & \\
\hline
\end{tabular}

Being in the frontline of the fight against COVID-19, deemed more vulnerable to the harmful effects of this disease than other groups in society, the vast major- 
ity of the nursing staff (91\%) showed moderate levels of perceived stress. A result far higher than that what was documented by other articles. For instance, Salari et al. study reported that the overall prevalence of stress among the healthcare workers caring for COVID-19 patients was 45\% [23]. A further lower percentage was documented by Morin and Carrier which showed that only $15.8 \%$ of health care workers in China, had stress [24]. The higher level of stress among participants in our studies can be attributed to the lack of training about facing public health emergencies among the studied nurses.

Sixty two percent of the nurses in our study had moderate to severe anxiety. A similar study in Saudi Arabia showed that $68.5 \%$ of studied participants had moderate to severe anxiety level in healthcare workers [25]. Several studies reported a percentage of anxiety of $45 \%$ [26] [27] and 41.9\% [28] [29] among the health workers. A further lower percentage was reported in Omani study, in which $28.9 \%$ of healthcare workers had moderate to severe anxiety [30]. However, a meta-analysis showed that the pooled prevalence of anxiety among the health workers to be $23.21 \%$, and $88 \%$ of those workers had moderate to severe levels of anxiety [31]. Similarly, another meta-analysis reported that the prevalence of anxiety in nurses is $22.8 \%$ [23]. However, a Chinese study revealed anxiety prevalence of $18.5 \%$ among both health care workers and adults from general population [24]. In KSA, most nurses in hospitals are migrant from different countries. Being away from home and families in addition to the heavy workloads, all these may result in high level of medical errors, anxiety, and stress.

Workplace stress increases sleep disturbances in the medical staff, especially nurses. Our study showed that $15 \%$ of the participants had clinical insomnia, a result lower than that documented by other studies. A study was conducted in China revealed the rates of insomnia among health care workers was 20\% [24]. However, number of articles documented a prevalence of $32 \%$ - 36\% [25] [26] [31] [32]. Higher prevalence was reported in Oman and Greece where $40.1 \%$ and 49.7\% of participants had sleep disorders [30] [33]. Several factors that can contribute to sleep disturbances among the nurses that are treating the COVID-19 patients. One of these factors is the stress of being infected, and the lack of definite treatment.

It is well documented in number of articles that anxiety, insomnia, and distress symptoms were significantly higher in females compared to males [25] [26] [31]. However, our results showed no difference in anxiety, stress and insomnia between males and females, a result similar to that documented in Tselebis et al. study [33]. In addition, significant relation was observed between age and insomnia, anxiety and perceived stress in the studied sample, in line with studies done in Austria and Greece [33] [34]. In China, it was concluded that health care workers between 31 - 40-years old, were more worried about infecting their families compared with other age groups [35]. Additionally, a Chinese study reported that age was negatively associated with depression, anxiety and insomnia [36]. 


\section{Limitations of the Study}

Number of participants deemed somewhat low, which represents the major limitation in this study. This was due to the limited timeframe that has been approved by the hospital and the shortage of nursing staff. The fact that only nurses participated in this study limits the generalizability of its results. Limited generalizability due to potential low sample.

\section{Conclusion}

Our study showed a considerable level of stress, anxiety and clinical insomnia among nursing staff, about $91 \%$ complains of moderate perceived stress, severe anxiety $34 \%$ and clinical insomnia $15 \%$. There was a correlation between levels of stress, anxiety and clinical insomnia and age of the studied nurses with statistically significant difference, on the other hand no significant difference with gender.

\section{Acknowledgements}

The authors are very thankful to the Deanship of Scientific Research, Prince Sattam bin Abdulaziz University \& Saudi Electronic University for supporting this work.

\section{Conflicts of Interest}

The authors declare no conflicts of interest regarding the publication of this paper.

\section{References}

[1] Wang, C., Horby, P.W., Hayden, F.G. and Gao, G.F. (2020) A Novel Coronavirus Outbreak of Global Health Concern. The Lancet, 395, 470-473.

https://doi.org/10.1016/S0140-6736(20)30185-9

[2] WHO (2020) Rolling Updates on Coronavirus Disease (COVID-19). https://www.who.int/emergencies/diseases/novel-coronavirus-2019/events-as-theyhappen

[3] Wang, W., Chen, S., Liu, I., et al. (2004) Detection SARS in Throat and Saliva Early Diagnosis. Emerging Infectious Diseases, 10, 1213-1219. https://doi.org/10.3201/eid1007.031113

[4] Sri Santosh, T., Parmar, R., Anand, H., Srikanth, K. and Saritha, M. (2020) A Review of Salivary Diagnostics and Its Potential Implication in Detection of Covid-19. Cureus, 12, e7708. https://doi.org/10.7759/cureus.7708

[5] Arrogante, O. and Aparicio-Zaldivar, E. (2017) Burnout and Health among Critical Care Professionals: The Mediational Role of Resilience. Intensive and Critical Care Nursing, 42, 110-115. https://doi.org/10.1016/j.iccn.2017.04.010

[6] Li, W., Yang, Y., Liu, Z.H., et al. (2020) Progression of Mental Health Services during the COVID-19 Outbreak in China. International Journal of Biological Sciences, 16, 1732-1738. https://doi.org/10.7150/ijbs.45120

[7] Jansson, M., Liao, X. and Rello, J. (2020) Strengthening ICU Health Security for a Coronavirus Epidemic. Intensive and Critical Care Nursing, 57, Article ID: 102812. 
https://doi.org/10.1016/j.iccn.2020.102812

[8] Xiang, Y.T., Yang, Y., Li, W., et al. (2020) Timely Mental Health Care for the 2019 Novel Coronavirus Outbreak Is Urgently Needed. The Lancet Psychiatry, 7, 228-229. https://doi.org/10.1016/S2215-0366(20)30046-8

[9] Huang, Y. and Zhao, N. (2020) Generalized Anxiety Disorder, Depressive Symptoms and Sleep Quality during COVID-19 Outbreak in China: A Web-Based CrossSectional Survey. Psychiatry Research, 288, Article ID: 112954. https://doi.org/10.1016/j.psychres.2020.112954

[10] Wankowicz, P., Szylinska, A. and Rotter, I. (2020) Assessment of Mental Health Factors among Health Professionals Depending on Their Contact with COVID-19 Patients. International Journal of Environmental Research and Public Health, 17, 5849. https://doi.org/10.3390/ijerph17165849

[11] Galedar, N., Toulabi, T., Kamran, A. and Heydari, H. (2020) Exploring Nurses' Perception of Taking Care of Patients with Coronavirus Disease (COVID-19): A Qualitative Study. Nursing Open, 8, 171-179. https://doi.org/10.1002/nop2.616

[12] Cai, Z., Cui, Q., Liu, Z., Li, J., Gong, X., Liu, J., Wan, Z., Yuan, X., Li, X., Chen, C., et al. (2020) Nurses Endured High Risks of Psychological Problems under the Epidemic of COVID-19 in a Longitudinal Study in Wuhan China. Journal of Psychiatric Research, 131, 132-137. https://doi.org/10.1016/j.jpsychires.2020.09.007

[13] Diomidous, M. (2020) Sleep and Motion Disorders of Physicians and Nurses Working in Hospitals Facing the Pandemic of COVID 19. Medical Archives, 74, 210-215. https://doi.org/10.5455/medarh.2020.74.210-215

[14] Khattak, S.R., Saeed, I., Rehman, S.U. and Fayaz, M. (2020) Impact of Fear of COVID19 Pandemic on the Mental Health of Nurses in Pakistan. Journal of Loss and Trauma, 26, 1-15. https://doi.org/10.1080/15325024.2020.1814580

[15] Al Ateeq, D.A., Aljhani, S., Althiyabi, I. and Majzoub, S. (2020) Mental Health among Healthcare Providers during Coronavirus Disease (COVID-19) Outbreak in Saudi Arabia. Journal of Infection and Public Health, 13, 1432-1437. https://doi.org/10.1016/j.jiph.2020.08.013

[16] Almater, A., Tobaigy, M., Younis, A., Alaqeel, M. and Abouammoh, M. (2020) Effect of 2019 Coronavirus Pandemic on Ophthalmologists Practicing in Saudi Arabia: A Psychological Health Assessment. Middle East African Journal of Ophthalmology, 27, 79-85. https://doi.org/10.4103/meajo.MEAJO 22020

[17] Alzaid, E., Alsaad, S., Alshakhis, N., Albagshi, D., Albesher, R. and Aloqaili, M. (2020) Prevalence of COVID-19-Related Anxiety among Healthcare Workers: A Cross-Sectional Study. Journal of Family Medicine and Primary Care, 9, 4904-4910. https://doi.org/10.4103/jfmpc.jfmpc $674 \quad 20$

[18] Temsah, M.H., Al-Sohime, F., Alamro, N., Al-Eyadhy, A., Al-Hasan, K., Jamal, A., et al. (2020) The Psychological Impact of COVID-19 Pandemic on Health Care Workers in a MERS-CoV Endemic Country. Journal of Infection and Public Health, 13, 877-882. https://doi.org/10.1016/j.jiph.2020.05.021

[19] Levenstein, S., Prantera, C., Varvo, V., et al. (1993) Development of the Perceived Stress Questionnaire: A New Tool for Psychosomatic Research. Journal of Psychosomatic Research, 37, 19-32. https://doi.org/10.1016/0022-3999(93)90120-5

[20] Spitzer, R.L., Kroenke, K., Williams, J.W. and Löwe, B. (2006) A Brief Measure for Assessing Generalized Anxiety Disorder: The GAD-7. Archives of Internal Medicine, 166, 1092-1097. https://doi.org/10.1001/archinte.166.10.1092

[21] Morin, C. (1993) Insomnia, Psychological Assessment and Management. Stress Medications, 48, 756-757. 
[22] Millar, R.C. (2020) Nursing a Patient with Covid-19 Infection. ISSN Pending. Inaugural Issue, 1, 4-8.

[23] Salari, N., Khazaie, H., Hosseinian-Far, A., et al. (2020) The Prevalence of Stress, Anxiety and Depression within Front-Line Healthcare Workers Caring for COVID19 Patients: A Systematic Review and Meta-Regression. Human Resources for Health, 18, 1-14. https://doi.org/10.1186/s12960-020-00544-1

[24] Morin, C.M. and Carrier, J. (2020) The Acute Effects of the COVID-19 Pandemic on Insomnia and Psychological Symptoms. Sleep Medicine, 77, 346-347. https://doi.org/10.1016/j.sleep.2020.06.005

[25] Alenazi, T.H., BinDhim, N.F., Alenazi, M.H., et al. (2020) Prevalence and Predictors of Anxiety among Healthcare Workers in Saudi Arabia during the COVID-19 Pandemic. Journal of Infection and Public Health, 13, 1645-1651. https://doi.org/10.1016/j.jiph.2020.09.001

[26] Lai, J., Ma, S., Wang, Y., et al. (2020) Factors Associated with Mental Health Outcomes among Health Care Workers Exposed to Coronavirus Disease 2019. JAMA Network Open, 3, e203976. https://doi.org/10.1001/jamanetworkopen.2020.3976

[27] Şahin, M.K., Aker, S., Şahin, G. and Karabekiroğlu, A. (2020) Prevalence of Depression, Anxiety, Distress and Insomnia and Related Factors in Healthcare Workers during COVID-19 Pandemic in Turkey. Journal of Community Health, 45, 1168 1177. https://doi.org/10.1007/s10900-020-00921-w

[28] Khanal, P., Devkota, N., Dahal, M., Paudel, K. and Joshi, D. (2020) Mental Health Impacts among Health Workers during COVID-19 in a Low Resource Setting: A Cross-Sectional Survey from Nepal. Global Health, 16, Article No. 89.

https://doi.org/10.1186/s12992-020-00621-Z

[29] Salari, N., Khazaie, H., Hosseinian-Far, A., et al. (2020) The Prevalence of Sleep Disturbances among Physicians and Nurses Facing the COVID-19 Patients: A Systematic Review and Meta-Analysis. Global Health, 16, Article No. 92. https://doi.org/10.1186/s12992-020-00620-0

[30] Badahdah, A.M., Khamis, F. and Al Mahyijari, N. (2020) Sleep Quality among Health Care Workers during the COVID-19 Pandemic. Journal of Clinical Sleep Medicine, 16, 1635. https://doi.org/10.5664/jcsm.8624

[31] Pappa, S., Ntella, V., Giannakas, T., Giannakoulis, V.G., Papoutsi, E. and Katsaounou, P. (2020) Prevalence of Depression, Anxiety, and Insomnia among Healthcare Workers during the COVID-19 Pandemic: A Systematic Review and Meta-Analysis. Brain, Behavior, and Immunity, 88, 901-907. https://doi.org/10.1016/j.bbi.2020.05.026

[32] Zhang, C., Yang, L., Liu, S., et al. (2020) Survey of Insomnia and Related Social Psychological Factors among Medical Staff Involved in the 2019 Novel Coronavirus Disease Outbreak. Frontiers in Psychiatry, 11, Article No. 306.

https://doi.org/10.3389/fpsyt.2020.00306

[33] Tselebis, A., Lekka, D., Sikaras, C., et al. (2020) Insomnia, Perceived Stress, and Family Support among Nursing Staff during the Pandemic Crisis. Healthcare, 8, 434. https://doi.org/10.3390/healthcare8040434

[34] Pieh, C., O’Rourke, T., Budimir, S. and Probst, T. (2020) Relationship Quality and Mental Health during COVID-19 Lockdown. PLoS ONE, 15, e0238906. https://doi.org/10.1371/journal.pone.0238906

[35] Cai, H., Tu, B., Ma, J., Chen, L., Fu, L., Jiang, Y., et al. (2020) Psychological Impact and Coping Strategies of Frontline Medical Staff in Hunan between January and March 2020 during the Outbreak of Coronavirus Disease 2019 COVID-19 in Hubei, 
China. Medical Science Monitor, 26, e924171.

https://doi.org/10.12659/MSM.924171

[36] Zhou, Y., Wang, W., Sun, Y., Qian, W., Liu, Z., Wang, R., et al. (2020) The Prevalence and Risk Factors of Psychological Disturbances of Frontline Medical Staff in China under the COVID-19 Epidemic: Workload Should Be Concerned. Journal of Affective Disorders, 277, 510-514. https://doi.org/10.1016/j.jad.2020.08.059 